\title{
Conspicuous epiphytic growth of a Neotyphodium endophyte on perennial ryegrass inflorescences
}

\author{
M.J. CHRISTENSEN ${ }^{\mathrm{a}}$ and K. SAULSBURY ${ }^{\mathrm{b}}$ \\ agResearch Grasslands, Private Bag 11008, Palmerston North, New Zealand \\ ${ }^{b} P G G$ Wrightson, Kimihia Research Centre, Lincoln \\ mike.christensen@agresearch.co.nz
}

Conspicuous white mycelial growth was noted on inflorescences of a small percentage of perennial ryegrass plants (cultivar 'Extreme') that were being managed for seed production. The inflorescences with the epiphytic growth were distorted, with the amount of distortion varying greatly. This cultivar was infected with a Neotyphodium endophyte, strain AR6, that enhances the persistence of the host without inducing ryegrass staggers in grazing livestock. Such mycelial growth had never been previously observed on seed crops of perennial ryegrass cultivars infected with a Neotyphodium endophyte and so studies were carried out to identify the causal fungus and to describe its effects on the host grass.

The causal fungus was isolated from distorted inflorescences and the resulting colonies were indistinguishable from those isolated from symptomless inflorescences. Colonies from both the distorted and symptomless inflorescences produced many colourless conidia on short tapering conidiophores and these were the same shape and size as those reported for strain AR6. Examination of thin sections of the distorted inflorescences by light microscopy revealed that abundant hyphae were present both within and outside of the inflorescence tissues. Hyphae were also present in the phloem of some large vascular bundles. Hyphae were observed between epidermal cells connecting the endophytic and epiphytic growth. Epiphytic hyphae closest to the leaf contained many vacuoles and were poorly stained while those furthest from the leaf had dense cytoplasm and were densely stained. Hyphae within vascular bundles had dense cytoplasm whereas some hyphae in the mesophyll contained diffuse cytoplasm and vacuoles.

Not only is the presence of epiphytic hyphae visible to the naked eye unknown with Neotyphodium endophytes, but so is the distortion of inflorescences. The diffuse cytoplasm and numerous vacuoles of some hyphae are also atypical. The epiphytic growth had similarities with that of the stromata of Epichloe spp. in that it was present only on reproductive tillers and only on the inflorescences. However, unlike the stromata of Epichloë spp. which prevent emergence of inflorescences ("choke" disease) the inflorescences were able to emerge.

The observation that conspicuous epiphytic growth can occur on inflorescences of ryegrasses infected with a Neotyphodium endophyte provides insights into the interaction of Epichloë and Neotyphodium spp. with host grasses. In vegetative plants the growth of these endophytes is fully synchronised with that of the host grass, with tissues being colonised as they are developing after which no further hyphae are formed. The formation of stromata by Epichloë spp. and the conspicuous epiphytic growth of Neotyphodium strain AR6 result from ongoing hyphal growth; a loss of the tightly synchronised regulation. An explanation for these developments is that a plant-produced signal that maintains the synchronisation of hyphal growth with that of the host grass has become ineffective. 